\title{
UrusSisa: An Intelligent System for Integrated Solid Waste Management
}

\author{
Latifah Abd Manaf (Corresponding author) \\ Department of Environmental Sciences \\ Faculty of Environmental Studies \\ Universiti Putra Malaysia \\ 43400 UPM Serdang \\ Selangor, MALAYSIA
}

Tel: 60-3-8946-6747Ｅ-mail: latifah@env.upm.my

\author{
Hassan Basri, Noor Ezlin Ahmad Basri \\ Department of Civil and Structured Engineering \\ Faculty of Enginering \\ Universiti Kebangsaan Malaysia \\ 43600 Bangi, Selangor, MALAYSIA
}

The research is sponsored by National Science Fellowship under Ministry of Science, Technology and Innovation, Malaysia

\begin{abstract}
UrusSisa is an expert system for selecting and designing solid waste technology. It can improve the process of selecting the best solid waste technology, and to make the knowledge of preliminary design of solid waste technology available. Knowledge based of UrusSisa consists of priority ranking using Analytical Hierarchy Process (AHP), and preliminary design of recommendation technology. AHP involves structuring multiple choice criteria into a hierarchy, assessing the relative importance of these criteria, and determining an overall ranking of the alternatives. Preliminary design of solid waste technology includes recycling, composting, incineration, and sanitary landfill. The performance of prototype has been tested by using case study.
\end{abstract}

Keywords: Integrated solid waste management, Analytical Hierarchy Process

\section{Introduction}

Solid waste can be classified as unwanted materials left over from manufacturing process, or refuse from places of human habitation. Solid waste management is an integral part of urban and environmental management of each city. In developing countries, these services fall short from the desired level as the system being adopted are outdated and inefficient. Extremely low priority is given to the area of waste handling and disposal resulting in budgetary limitations and weak infrastructure to handle one of the most important problems in most urban areas.

The total amount of solid waste generated in Malaysia was about 16,000 tons per day with the average per capita generation rate of about $0.88 \mathrm{~kg} /$ day (Ministry of Housing and Local Government 2002). The amount generated is expected to increase due to rapid economic and population growth. At present, landfilling is the only method for disposal and most of these landfill sites are open dumps which is nearly full. To develop a new landfill site is difficult because of land scarcity and increasing of land prices especially in urban areas.

Today, an integrated solid waste management requires a more formal structure of facilities and political actions, not only within the community but also the state and federal governments. Armed with technical and economic resources, managers of solid waste system must integrate of all aspects solid waste management activities, from generation through disposal. Therefore, Integrated Solid Waste Management Program has been developed in Malaysia to divert municipal solid waste from disposal sites. 


\section{Analytical Hierarchy Process in Solid Waste Management}

Analytical Hierarchy Process (AHP) is amongst the most well known methods of Multi Criteria Decision Making, introduced by Saaty (1980). AHP can be defined as a hierarchical analysis methodology supporting rational decision making by simplifying a complicated problem (Saaty 1995).

Decision making in solid waste management involved a complex problems. Both tangible and intangible criteria need to be prioritized in a decision making process. Intangible criteria such as political and social factors take precedence over tangibles criteria such as economic and technical factors. AHP is methods that improve the understanding of complex decisions by decomposing the problem in a hierarchical structure. The incorporation of all relevant decision criteria, and their pair wise comparison allows the decision maker to determine the trade-offs among objectives.

A major strength of AHP is the pairwise comparison where the influence of the elements of a particular level over those of a lower level is measured. The comparison is based on an expert's opinion and experience gained from the observation and continuous learning of system behavior. Other advantage of AHP is that it has the ability to checking the consistency of judgments. This consistency ratio is important to ensure the judgments were consistent and that the final decision is made well.

The AHP is based on three principles: decomposition of the decision problem; comparative judgments of the elements; and synthesis of the priorities. The first step is to structure the decisions of the problem in a hierarchy (Fig. 1). The goal of the decision, "to choose the best technology for solid waste management", is at the top level of the hierarchy. The next level consists of the criteria relevant for this goal and at the bottom level are the alternatives to be evaluated.

The second step is the pairwise comparison between elements in structural hierarchy. For this relative comparison, the fundamental scale is as in Table 1 can be used. It allows expressing the comparisons in verbal terms, which are then translated to the corresponding numbers.

In the third step, the comparisons are being synthesized to get the priorities of the alternatives with respect to each criterion and the weights of each criterion with respect to the goal. The validity of pairing comparisons outcome is obtained by checking consistency, in which the consistency ratio is less than 0.1 can be accepted. However, if the consistency ratio is more than 0.1 , the pairwise comparison needs to be reevaluated. The consistency ratio is considered important as it indirectly able to control bias evaluation made by the domain expert that may inclined towards their own respective experiences, during the process of pair wise comparison. This is mainly due to expert's background in certain areas may highly influence the evaluation process. Even though there are some differences made by the experts, the consistency value that is less than 0.1 can be accepted.

\subsection{Criteria in Decision Making}

To extend the life span of landfills sites, the reduction of amount of wastes to be disposed off is crucial. Solid waste diversion could be implemented by technologies such as recycling, composting or incineration. The effectiveness of these technologies depends on many criteria such as political support, technical expertise, environmental impact, market for end-products and community involvement.

(1) Political support criteria

A political support is important because the final decision to select a technology is very much depended on it. A strong political support will ensure that the chosen technology is acceptable for a long time. Normally, technology selection is indirectly affected by the current political situations, whereby the leader developed their own favourite technologies.

(2) Technical expertise criteria

Technical expertise is referred to the high level of workers qualifications. Normally incinerator, a higher-end technology, requires workers with higher technical expertise to operate the system. Some waste technologies such as recycling and composting are relatively less complicated process and the requirement of technical expertise is not too critical.

(3) Environmental impact criteria

Technologies for solid waste management should be able to eliminate or reduce any potential environmental hazard to the environment. Environmental impact is potential to create problem such as public health nuisance and pollution to the environment. As an example, the principal potential negative impacts of a compost operation on the environment would be the lowering of the quality of water and air resources and the compromising of the public health and well being by attracting and breeding vectors and rodents. It should be emphasised that these impacts are potential impacts and that they would become actual only when an inadequate technology or methodology was used, a normally adequate management was improperly applied, and preventive or corrective measures were not taken.

(4) Market of end-product criteria 
Marketability of the end-products is an important criterion to ensure the success of an integrated solid waste management. Various end-products will be generated by solid waste technologies. Valuable materials will be recovered by recycling, compost product is produced by aerobic composting process, methane gas is obtained during anaerobic digestion process and renewable energy is produced by Refuse Derived Fuel (RDF). Marketability of the end-products should be analysed before a technology is to be selected to ensure that there will be demands for the products.

\section{(5) Community involvement criteria}

Community involvement is also considered crucial and should not be denied. There were cases of closing down various waste facilities due to objections from the community surrounding. It was shown that technologies which require intensive community participation such as segregation at source will pose a higher risk of failure especially in most developing countries. Certain technology, for example incineration, requires that the feedstock to be separated well to ensure the process runs smoothly.

\subsection{Solid Waste Management Alternatives}

A wide variety of alternative programs and technologies are presently available for the management of solid wastes. Due to the large number of participants in a decision-making process, the selection of proper mixture of alternatives technologies has become a more difficult task.

Based on hierarchy of integrated solid waste management, three technologies were chosen as alternatives; they are recycling, composting and incineration. However, sanitary landfill is not considered as an alternative because it must be developed in whatever system being chosen. Landfilling is always required no matter what intermediate treatment process is introduced. Be it incineration, composting, separation or recycling, there will always be residue left that has to be landfilled.

\section{(1) Recycling technology}

In most developing countries recycling activities are done informally mainly by scavengers at landfill sites. Recycling process started by the collection of valuable waste from waste generators, followed by processing and reprocessing phase. The recyclables are collected from curbsides, drop-off or buy-back centers. Recycling technology is considered important because it able reduce 20 percent of waste that must be disposed off in landfills. There are many benefits offer by recycling technology, such as to save the current exchange, to conserve the nature, to save the energy use, and to reduce the landfill life span. Among the valuable materials to recycle are aluminum, paper and cardboard, plastic, glass, and metal. Recycling is not a new a technology even in Malaysia. The recycling campaign was launched throughout the region in 1993. However the program failed in many regions due to lack of involvement from the public and factories. Therefore, on the 2nd December 2000, the Ministry of Housing and Local Authority re-launched the campaign for the second phase. The date 11th November was selected as the National Recycling Day.

\section{(2) Composting technology}

Composting is a control process where the organic material was biodegrade by the microorganisms to produce the black and stable compost. Composting process can be done as a passives piles, turned windrow, aerated static piles or in-vessel systems. All the systems have the same biological principles, but they differ by the aeration system. Composting offers many benefits such as to increase diversion rate from the waste disposal areas (50\%), compost products for soil amendments, promotion to an environmentally friendly practice and to reduce transportation costs. In Malaysia, composting is a one of the common practice to handle agriculture waste. However, presently there is no application for municipal solid waste, although almost 50 percent of the waste is organic materials.

(3) Incineration technology

Incineration is a chemical process where carbon, hydrogen and a few elements mix together with oxygen to produce heat energy. This technology is able to reduce toxicity, reactivity and high volume of waste effectively (can divert $85 \%$ of municipal waste from disposal site). However, it is very costly and must be operated by highly technical expertise. The three common incineration technologies available currently are mass burning, refuse-derived fuel and modular systems. Incineration is not a new technology in Malaysia as it is being used to treat hazardous waste as well. However, the implementation of incineration technology to treat municipal solid waste received strong objections from the public mainly due to health and environmental risks, high capital and operation costs and higher risks of technological failure due to the imported technology from abroad that has not been proven successful in the region.

\section{Components of UrusSisa Knowledge Base}

UrusSisa, prototype of expert system, is designed to aid the development of an effective solid waste management for Malaysia. The prototype was developed by phases; knowledge acquisition process from literature study initially, then interaction with the human experts who posses wide experience in the related areas, and eventually site observations. The knowledge gathered was then codified using an open source programming language (Preprocessor Hypertext - 
PHP) and MySQL as a database. An internet-based programming language was selected for easy access and usage in various locations worldwide.

The three broad categories of expertise sources were identified and selected to extract the knowledge base for prototype UrusSisa [a] textbooks and manuals; [b] domain experts; and [c] research publications. A complete understanding of the whole domain required a combination of multiple sources of expertise. Furthermore, multiple sources of expertise also important to increase the quality of knowledge base by avoid bias towards a single view, conflicting views manifested by several different experts, and handicapped by availability constraints of any one source of expertise..

The knowledge acquisition process for development prototype UrusSisa could be categorised into three phases:

- Phase I

Text analysis was done in Phase I to extract the contents from 22 textbooks and manuals related to the domain area. An understanding on the concepts, techniques, and the requirements of solid waste management especially recycling, composting and incineration is obtained in this phase. The knowledge extracted was then organized according to their respective tasks and become the foundation of the prototype knowledge base. Any conflicting information was rationalized and resolved.

○ Phase II

Phase II included interview sessions with 11 selected human experts and site observations. The acquired knowledge was used to strengthen, improve and expand the knowledge base of the prototype. By this process, the knowledge on solid waste management acquired were adapted to the Malaysian conditions. This is due to the reason that most textual knowledge sources acquired in Phase I were originated from abroad.

Site observations were done by observing the daily tasks for solid waste management activities. This method is more flexible as it does not take too much of the experts' valuable time, which is done naturally during their daily work.

○ Phase III

Phase III involved analysis of recent research publications such as journals and proceedings of conferences. This was done to strengthen, improve and expand the knowledge base by adding the latest findings and experiences.

In general, the UrusSisa architecture consists of two main components; priority ranking of technology using AHP technique, and the preliminary design of solid waste management technology. This division was taken place so that the explanation regarding their roles and functions could be done without many problems. In addition, the division was also important to help the users to understand the expert system architecture.

\section{a. Priority ranking of technology using AHP}

Consultation session using AHP initially started with six phases of pairwise comparison process; [1] criteria against objectives, [2] alternatives against political support, [3] alternatives against technical expertise, [4] alternatives against environmental impacts, [5] alternatives against marketability of products, [6] alternatives against public participation, and further with the process of identifying the benefit priority value. These are the core components of UrusSisa knowledge base. Figure 2 shows the main modules in priority ranking of technology using AHP, which include:

$\checkmark$ matrix of comparison module;

$\square$ priority analysis module;

$\square$ cost analysis module; and

$\square$ benefit-cost ratio module.

\section{b. Preliminary design of technology}

Preliminary design of a solid waste management is the major component of the knowledge base prototype, which includes:

$\begin{array}{ll}\square & \text { preliminary design for recycling } \\ \square & \text { preliminary design for composting } \\ \square & \text { preliminary design for incineration } \\ \square & \text { preliminary design for sanitary landfill }\end{array}$

From the four components above, each component will have their own individual modules. Basically the modules developed for the preliminary design of recycling are similar to the modules for composting, and incineration. For example, modules for preliminary design of recycling consists of (Fig. 3):

口 collection systems

口 area design 


$\begin{array}{ll}\square & \text { storage } \\ \square & \text { operation and equipment } \\ \square & \text { material preparation } \\ \square & \text { processing } \\ \square & \text { environmental issues } \\ \square & \text { siting location } \\ \square & \text { market planning }\end{array}$

Production rules was used to represent the knowledge of modules. A production rule resembles a simple sentence. It consists of a condition part, IF, on the left hand side, and an action part (THEN) on the right hand side. If the condition of a rule is satisfied by the working memory, the rule becomes applicable and will be fired by the inference engine. Therefore prototype UrusSisa can act and mimic like human experts in order to give recommendation and suggestion on preliminary design of technology. The following are examples of selecting a suitable recycling collection system using production rules technique:

If $\quad$ (\$public $==$ yes)

\{echo "frequency of collection recommended is $<$ font color=red $>$ weekly $</$ font $>$ because this will increase the percentage of participation by the community and the rate of recycling. Research done by EPA (1994), shows that the recycling program that capable of achieving high percentage of community participation recycling rate practise a weekly collection frequency during their operations"\}

else if ( $\$$ public $==$ no)

\{ "frequency of collection recommended is $<$ font color $=$ red $>$ twice weekly $<$ because this will reduce cost for the whole recycling program, instead it will be spent for public education.”\}

else $\quad$ echo "No data input. Please re-enter.";

\section{Prototype Verification and Validation Using Case Studies}

There is currently no formal approach for assessing prototype performance which is applicable universally. Many prototypes were tested based on case studies, the results of which were analysed internally by the system developers themselves (Berrais 1992). In the case of the UrusSisa, its performance was evaluated internally by the system developer herself and solid waste management experts. One case study was performed; Port Dickson Municipal Council; to evaluate the conceptual design for solid waste management technology. This gave some measure of the accuracy of its knowledge base. Finally, the user-friendliness of the prototype's user interface was evaluated.

\subsection{Case Study: Port Dickson Municipal Council}

Port Dickson Municipal Council - MPPD (formerly known as Port Dickson District Council) is located in Negeri Sembilan. The total area for this municipality is $40 \mathrm{~km}^{2}$ and serves a population of 106,000 . Solid waste generation is mixed at the rate 70 tonnes per day and it was collected by the municipality and contracted company. Solid waste will be disposed at Bukit Palong (64.7 acre), Sua Betong (6 acre) or Pengkalan Kempas (3 acre). However these disposals area is nearly filled and new disposal site must be identified. Implementation of solid waste technology such as recycling, composting and incineration is important to make life span of disposal site is longer.

Expert from MPPD was consulted to get the pairwise comparison value and solid waste input. Analysis AHP shows that the combination of two or three technology such as A4, A7, A6 and A5 have the most benefits, with relative weights of $0.165,0.159,0.153$ and 0.144 , respectively. On the other hand the single technology such as A1, A2 and A3 have much lower values of relative weights in the range of $0.122-0.129$. It is based on benefit hierarchy which indicates that technical expertise has the highest relative weight of 0.420 among all other criterias considered. It is followed by political support (0.315), environmental impact (0.127), market of end-product (0.100) and community involvement (0.038).

Cost hierarchy shows that combination of recycling and incineration (A7) technology has the most benefits having a relative weight of 0.255 . It is followed by A7, A3, A6, A4, A1 and A2; their corresponding relative weights are 0.170 , $0.169,0.150,0.135,0.095$ and 0.091 .

In order to give the complete picture the overall benefit priorities (relative weights) were divided by the cost priorities. An overall normalized benefit-to-cost ratio was obtained for each system. Benefit-tocost ratio is shown that composting (A2) technology have the highest overall benefit-to-cost ratio, with a relative weight value of 0.189 . Recycling (A1) technology have the second relative weight of about 0.184 . The best system with highest benefit-to-cost ratios are A4, followed by A6, A7, A5 and A3, having relative weights of 0.165, 0.137, 0.126, 0.102 and 0.097. 
From AHP analysis, composting is recommended to manage solid waste problem from Port Dickson area. This recommendation is supported by the solid waste composition where $54 \%$ of Port Dickson waste is organic material. Beside residential area, tourism activities also contributed to highly composition of organic material. Composting technology can diverse $50 \%$ of waste generation rate from disposed to disposal site.

The next consultation session is a preliminary design of composting technology where users need to complete their Input Data first. This component is important to help user design a composting technology. There are 10 modules in this component which includes:

$\square$ composting system module;

$\square$ site design module;

$\square$ operation and quipment module;

口 storage module;

$\square$ feedstock condition module;

口 control parameter modul;

$\square$ parameter control module;

a environmental impact module;

$\square$ site requirement module; and

$\square$ marketing plan module.

\section{Conclusion}

UrusSisa is a prototype of expert system which can assists the decision maker to establish the most appropriate solid waste technology in an integrated manner. The critical decisions at the planning stage are strived by applying a state-of-the-art Multi Criteria Decision Making (MCDM) technique call the modified Analytical Hierarchy Process (AHP). This ensures that the solid waste management system will take into account the numerous relevant criteria such as political support, technical expertise, environmental impact, end-product market, community involvement, and cost of technology, and their relative importance in an objective manner.

Besides assists in selecting the best technology, UrusSisa also can helps in a preliminary design of the technology. Expertise in the knowledge base was acquired from 22 textual sources, reputed journal publications and solid waste practitioners in Malaysia. The intelligent system was developed using an internet-based platform, hence making it to be very easily accessible to users all over the world. In developing countries where expertise and resources are scarce, this inexpensive system is particularly useful in avoiding ad-hoc or ill-informed decisions which can be unnecessarily costly.

\section{References}

Berrais, A. (1992). A knowledge-based design tool to assist in a preliminary seismic design. PhD thesis. University of Leeds, UK.

Municipal of Housing and Local Government. (1999). Annual report section 4 - local government. Technical Section of the Local Government Division, Kuala Lumpur.

Saaty, T.L. (1980). The analytic hierarchy process. McGraw Hill Inc, New York.

Saaty, T.L. (1995). Decision making for leaders - the analytic hierarchy process for decisions in a complex world. RWS Publications, Pittsburg. 
Table 1. Translation of verbal scale into numerical scale (Saaty 1980)

\begin{tabular}{|l|c|}
\hline \multicolumn{1}{|c|}{ Verbal Scale } & Numerical Scale \\
\hline One element equally important to other & 3 \\
\hline One element moderately more important to other & 5 \\
\hline One element strongly more important to other & 7 \\
\hline One element very strongly more important to other & 9 \\
\hline One element extremely more important to other & $2,4,6,8$ \\
\hline Intermediate values between two scales & \\
\hline
\end{tabular}

Leve1 1: Goal

To choose the best solid waste manage ment technology

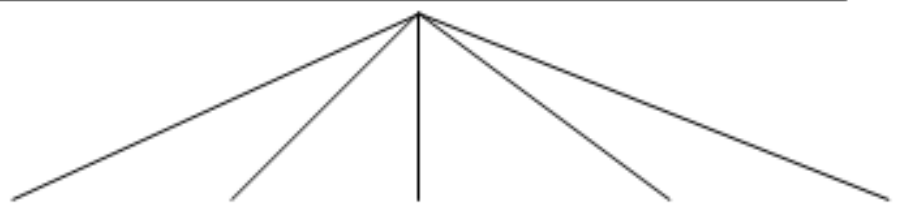

Leve1 2: Criteria

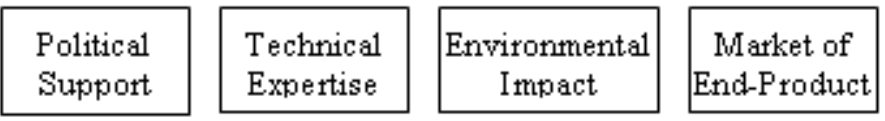

Community Involvement

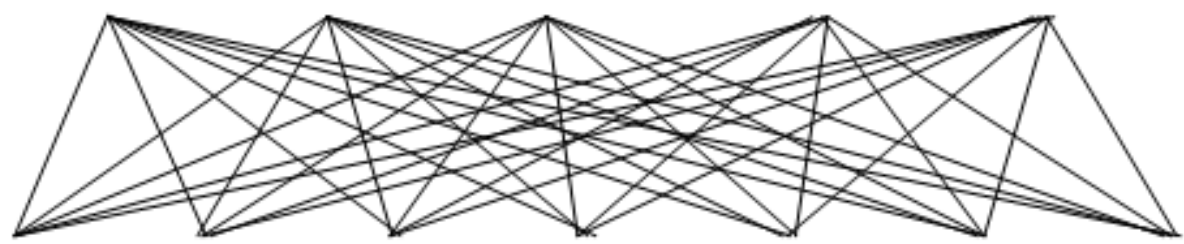

Leve1 3:

Alternatives

\begin{tabular}{|l|}
\hline A1 \\
A2
\end{tabular}

A4

\section{A5}

A6

where:

A1: Recycling

A2 : Composting

A3: Incineration

A4: Combinations of recycling + composting

A5: Combinations of recycling + incineration

A6: Combinations of composting + incineration

A7 : Combinations of recycling + composting + incineration

Figure 1. Hierarchy structure of solid waste management technology 


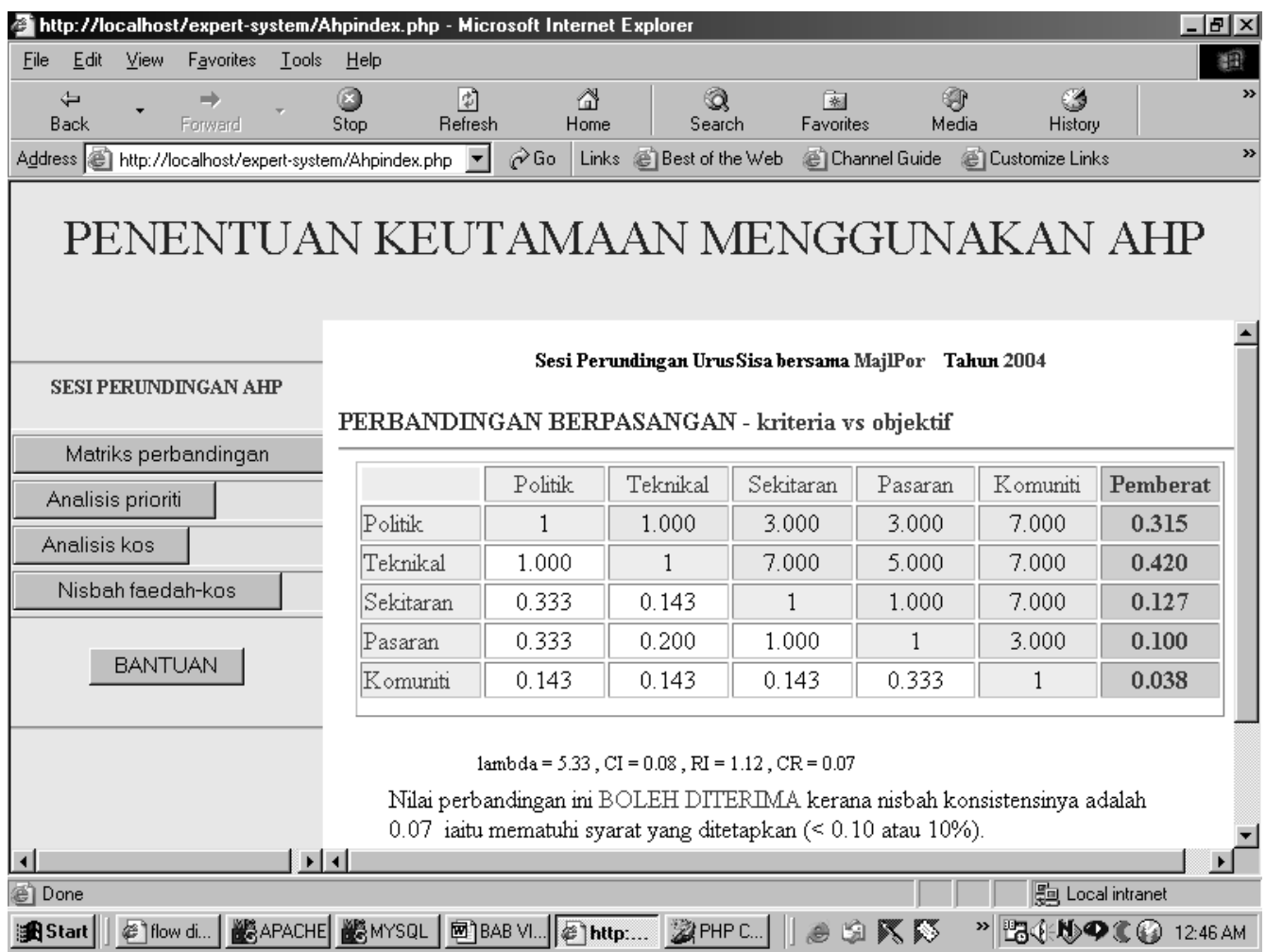

Figure 2. An example window for the priority ranking of the technology

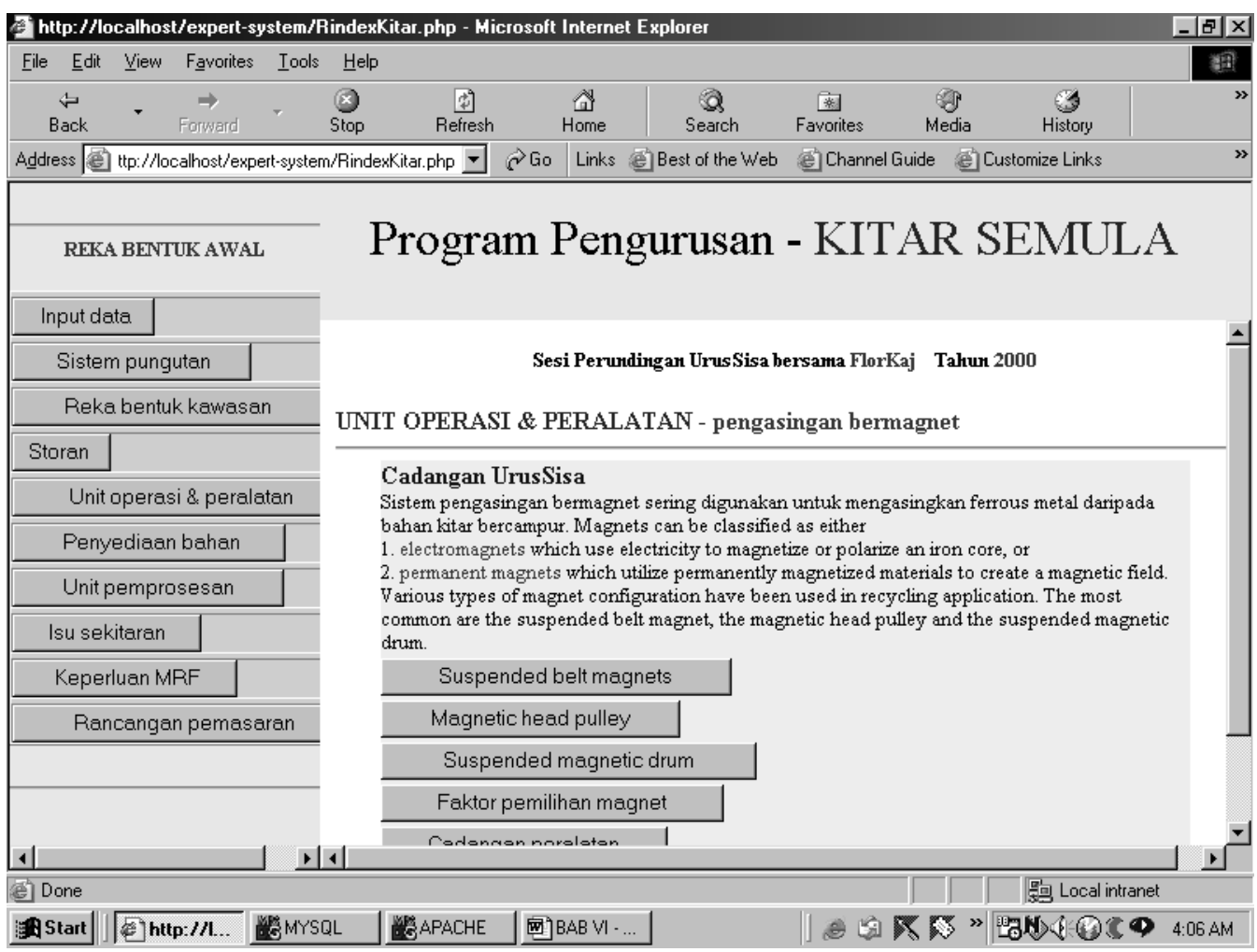

Figure 3. An example window for the preliminary design components of recycling 